\title{
Chinese Adversative Bèi Passive and Its English Translations in Literary Texts
}

\author{
Lester Zixian LIU \\ Applied Translation Studies \\ Division of Humanities \& Social Sciences \\ Beijing Normal University-Hong Kong Baptist University United International College \\ Zhuhai, China
}

\begin{abstract}
This research aims at finding the commonalities and distinctive features of translating bèi (被) passive into English in the context of literary texts and investigating different approaches translators adopt. Twelve English translation in the Spring 2015 edition of Pathlight will be analyzed as a way to develop translation resources. The main approaches to translation are: (1) retaining the original passive sentences and/or passive construction, (2) changing to corresponding active sentences, (3) changing into active sentences with the same narrative perspective, and (4) paraphrasing the original passives. Translation of adversative bèi passive sentences is evaluated from the perspectives of semantic equivalence and aesthetic effect in order to investigate whether they effectively and successfully express the original adversative meaning and represent the original aesthetic effect. Reasons for ineffective and unsuccessful semantic equivalence are analyzed, that include translators failing to recognize the adversative expression of bèi passive, and not paying sufficient attention to preserving the original lexical terms which express the adversative connotation and present the literary effect and adversative resultative compounds in bèi passive.

Keywords: adversative bèi passive, aesthetic effect, semantic equivalence, translation evaluation Cite as: LIU, L. Z. (2018). Chinese Adversative Bèi Passive and Its English Translations in Literary Texts. Arab World English Journal for Translation \& Literary Studies, 2 (2). DOI: http://dx.doi.org/10.24093/awejtls/vol2no2.4
\end{abstract}

